Check for updates

Cite this: RSC Adv., 2018, 8, 843

Received 24th September 2017 Accepted 17th December 2017

DOI: 10.1039/c7ra10568a

rsc.li/rsc-advances

\section{Construction of cost-effective bimetallic nanoparticles on titanium carbides as a superb catalyst for promoting hydrolysis of ammonia borane $\uparrow$}

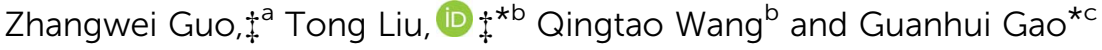 \\ Bimetallic cost-effective CoNi nanoparticles (NPs) are conveniently supported on titanium carbides \\ (MXene) by a simple one-step wet-chemical method. The synthesized CoNi/MXene catalysts are \\ characterized by XPS, TEM, STEM-HAADF and ICP-AES. The as-prepared CoNi NPs with a size of $2.8 \mathrm{~nm}$ \\ are well dispersed on the MXene surface. It is found that among the CoNi bimetallic system, $\mathrm{CO}_{0.7} \mathrm{Ni}_{0.3}$ \\ shows the best performance toward catalyzing ammonia borane (AB) decomposition with a turnover \\ frequency value of $87.6 \mathrm{~mol}_{\mathrm{H}_{2}} \mathrm{~mol}_{\mathrm{cat}}{ }^{-1} \mathrm{~min}^{-1}$ at $50{ }^{\circ} \mathrm{C}$. The remarkable catalytic performance is \\ attributed to the mild affiliation of MXene to NPs, which not only stabilizes NPs to maintain a good \\ dispersion but also leaves sufficient surface active sites to facilitate the catalytic reaction.
}

\section{Introduction}

In order to solve the global problems caused by heavy use of fossil fuels in the world, it is highly desirable to develop clean and sustainable energy sources and in turn decrease the consumption of traditional fossil fuels. ${ }^{1-5}$ Hydrogen, as an environmentally clean energy carrier, has been regarded as one of the most promising candidates to meet the increasing demands for an efficient and clean energy supply. ${ }^{6-9}$ Among various chemical hydrogen storage materials, ammonia-borane (AB) with a high hydrogen content (19.6 wt\%), high stability under ambient conditions, high solubility and nontoxicity, has been considered as a leading contender in promising chemical hydrogen-storage materials for various applications. ${ }^{10-12} \mathrm{Up}$ to now, intensive efforts have been made to achieve efficient $\mathrm{AB}$ decomposition, generating $3 \mathrm{~mol}$ of $\mathrm{H}_{2}$ per mole of $\mathrm{AB}$, through an efficient, economical and durable catalyst. Although, noble metal-based catalysts, such as $\mathrm{Pt}, \mathrm{Rh}$, and $\mathrm{Ru},{ }^{13}$ provided the highest activities to dehydrogenation of $\mathrm{AB}$, the high cost and scarcity of these catalysts hinders their industrial application. Alternatively, cost-effective metals have been recently developed. Especially, it is found that bimetallic systems usually

\footnotetext{
${ }^{a}$ College of Ocean Science and Engineering, Shanghai Maritime University, Haigang Ave 1550, 201306 Shanghai, China

${ }^{b}$ College of Materials Science and Engineering, Qingdao University of Science and Technology, Zhengzhou Rd 53, 266000 Qingdao, China. E-mail: liutong@qust.edu.cn 'Paul-Drude-Institut für Festkörperelektronik, Hausvogteiplatz 5-7, 10117 Berlin, Germany.E-mail: gao@pdi-berlin.de

$\dagger$ Electronic supplementary information (ESI) available. See DOI: $10.1039 / \mathrm{c} 7 \mathrm{ra} 10568 \mathrm{a}$

$\ddagger$ These authors contributed equally to this work.
}

show higher catalytic kinetics than their monometallic counterparts, due to the synergistic geometric and electronic effects of bimetallic systems, such as $\mathrm{Cu}-\mathrm{Ni}$, $\mathrm{Cu}-\mathrm{Co}$, Co-Ni. ${ }^{14-16}$ However, the aggregation of these catalysts always resulted in the tremendous loss of their active sites. To address this problem, different carriers such as graphene, metal-organic frameworks and carbon nanotubes were used to disperse metal nanoparticles (NPs). ${ }^{17-20}$ The results show that these carriers can effectively restrain the agglomeration of metal NPs and improve their catalytic activities. Recently, graphene-like transition metal carbide (MXene, $\left.\mathrm{Ti}_{3} \mathrm{C}_{2}\left(\mathrm{OH}_{x} \mathrm{~F}_{1-x}\right)_{2}\right)$ has been widely investigated as a promising carrier for new nanocatalyst. ${ }^{21-26}$ The abundant functional groups on MXene surface, such as $\mathrm{Ti}-\mathrm{OH}$ and Ti-F bonds, not only stabilize the nanoparticles during reduction but also improve the hydrophilicity of the resultant catalysts. ${ }^{27,28}$ However, there is rare report on catalytic properties of $\mathrm{Ti}_{3} \mathrm{C}_{2} \mathrm{X}_{2}$ supported NPs. In this work, for the first time, we synthesize a composite material of CoNi bimetallic nanoparticles supported on MXene via a simple one-step wetchemical method. Unexpectedly, the resultant CoNi/MXene nanocatalysts with $100 \%$ of $\mathrm{H}_{2}$ selectivity show extremely high catalytic activity and excellent durability toward $\mathrm{AB}$ decomposition.

\section{Experiment}

\section{Synthesis of CoNi/MXene}

The synthesis route of the CoNi/MXene nanocatalyst is shown in Scheme 1. In a typical experiment, $100 \mathrm{mg}$ MXene was dissolved in $2 \mathrm{~mL}$ water in a two-neck round-bottom flask $(30 \mathrm{~mL})$. Ultrasonication was required to get a uniform dispersion for 


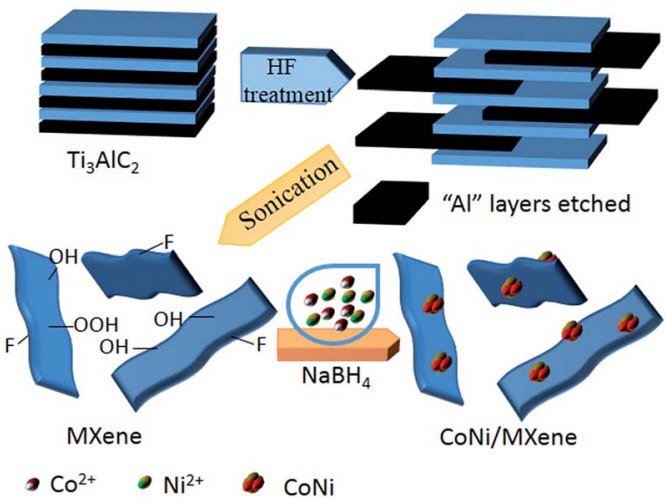

Scheme 1 Schematic representation of synthesis of the CoNi/MXene catalyst.

30 min. Then, $200 \mu \mathrm{L}$ cobalt chloride solution $\left(0.07 \mathrm{mmol} \mathrm{mL}^{-1}\right)$ and $200 \mu \mathrm{L}$ nickel chloride $\left(0.03 \mathrm{mmol} \mathrm{mL}^{-1}\right)$ were added into the MXene solution. The resulted mixture was stirred for 20 min with a rotating shaker $(220 \mathrm{rpm})$. A $0.5 \mathrm{~mL}$ aqueous solution of sodium borohydride $\left(\mathrm{NaBH}_{4}\right)\left(1.3 \mathrm{~mol} \mathrm{~L}^{-1}\right)$ was quickly added into the resulted mixture under vigorous stirring for $3 \mathrm{~h}$ at $0{ }^{\circ} \mathrm{C}$ using an ice bath to maintain the temperature. When the situ synthesis reaction was completed, $0.5 \mathrm{~mL}$ of aqueous solution containing $1 \mathrm{mmol} \mathrm{AB}$ was injected into the mixture using a syringe, a gas burette filled with water was connected to the reaction flask to measure the volume of released gas. For comparison, $\mathrm{CoNi} / \mathrm{vulcanxc-72}$ carbon (CoNi/XC-72), $\mathrm{CoNi} /$ graphene oxide (CoNi/GO) and $\mathrm{CoNi} / \mathrm{Al}_{2} \mathrm{O}_{3}$ reduced by $\mathrm{NaBH}_{4}$ were synthesized respectively by the similar method.

\section{Morphological, structural and compositional characterizations}

Transmission electron microscopy (TEM) images and highresolution STEM measurements were obtained using Tecnai G2 F30 S-Twin instrument with a field emission gun operating at $200 \mathrm{kV}$. X-ray photoelectron spectroscopy (XPS) measurement was performed with ESCALAB 250Xi spectrophotometer. The metal contents of the catalyst were analyzed using inductively coupled plasma atomic emission spectroscopy (ICP-AES) on Leeman PROFILE SPEC. Mass spectrometry (MS) analysis of the generated gas was performed using an OmniStar GSD320 mass spectrometer, wherein Ar was chosen as the carrying gas.

\section{Results and discussions}

Fig. 1 shows XPS spectra of CoNi/MXene in the survey, and C 1s, $\mathrm{Co} 2 \mathrm{p}$ and $\mathrm{Ni} 2 \mathrm{p}$ regions. As shown in Fig. 1a, the C 1s spectrum can be divided into several peaks, which corresponds to different kinds of bonds including $\mathrm{C}-\mathrm{Ti}, \mathrm{C}-\mathrm{C}, \mathrm{C}-\mathrm{OH}$, and $\mathrm{HO}-\mathrm{C}=\mathrm{O}$, respectively. Additionally, the presence of $\mathrm{F}$ and $\mathrm{O}$ indicate the introduction of functional groups such as $\mathrm{OH}$ and $\mathrm{F}$ on $\mathrm{Ti}_{3} \mathrm{C}_{2} \mathrm{X}_{2}$ surface (Fig. $\mathrm{S} 1$ and $\mathrm{S} 2 \dagger$ ), which not only enhances the hydrophilicity of the support but also facilitates to the stabilization of the synthesized CoNi NPs, leading a fine
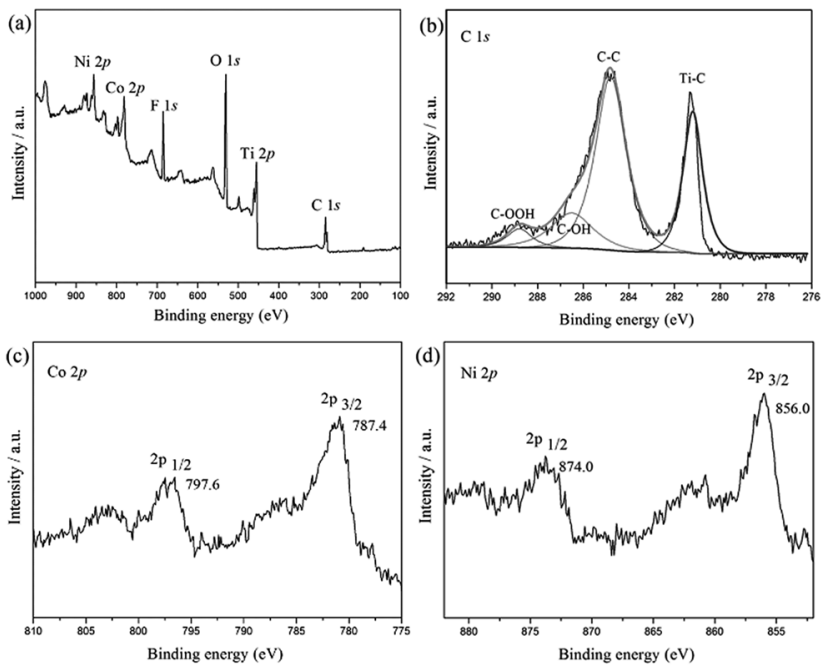

Fig. 1 Spectroscopic characteristics of $\mathrm{Co}_{0.7} \mathrm{Ni}_{0.3} / \mathrm{MXene}$. Survey spectrum of $\mathrm{Co}_{0.7} \mathrm{Ni}_{0.3} / \mathrm{MXene}(\mathrm{a})$, and XPS spectra of $\mathrm{C} 1 \mathrm{~s}, \mathrm{Co} 2 \mathrm{p}$ and $\mathrm{Ni} 2 \mathrm{p}(\mathrm{b}-\mathrm{d})$.

dispersion and good stability of the synthesized nanocatalyst in this heterogeneous system. The two peaks located at $787.4 \mathrm{eV}$ and $797.6 \mathrm{eV}$ can be assigned to elemental $\mathrm{Co}^{0} 2 \mathrm{p}_{3 / 2}$ and $\mathrm{Co}^{0}$ $2 \mathrm{p}_{1 / 2}$, respectively. While the $\mathrm{Ni}$ peaks corresponding to $\mathrm{Ni}^{0}$ $2 \mathrm{p}_{3 / 2}$ and $\mathrm{Ni}^{0} 2 \mathrm{p}_{1 / 2}$ are observed at $856 \mathrm{eV}$ and $874 \mathrm{eV}$, respectively. ${ }^{27,28}$ From the above results, it can be clearly demonstrated that the CoNi particles have been successfully anchored on MXene surface.

To further investigate the morphologies of resultant $\mathrm{CoNi}$ NPs, transmission electron microscopy (TEM) and high resolution TEM (HRTEM) are used. As seen in Fig. $2 \mathrm{a}$ and $\mathrm{S} 3, \uparrow$ the $\mathrm{Co}_{0.7} \mathrm{Ni}_{0.3}$ NPs have the good dispersion and no obvious aggregation has been happened. The average diameter of the NPs is about $2.8 \mathrm{~nm}$ (Fig. 2c inset). The narrow size and shape distributions benefit from the 'confine effect' from the functional $\mathrm{OH}$

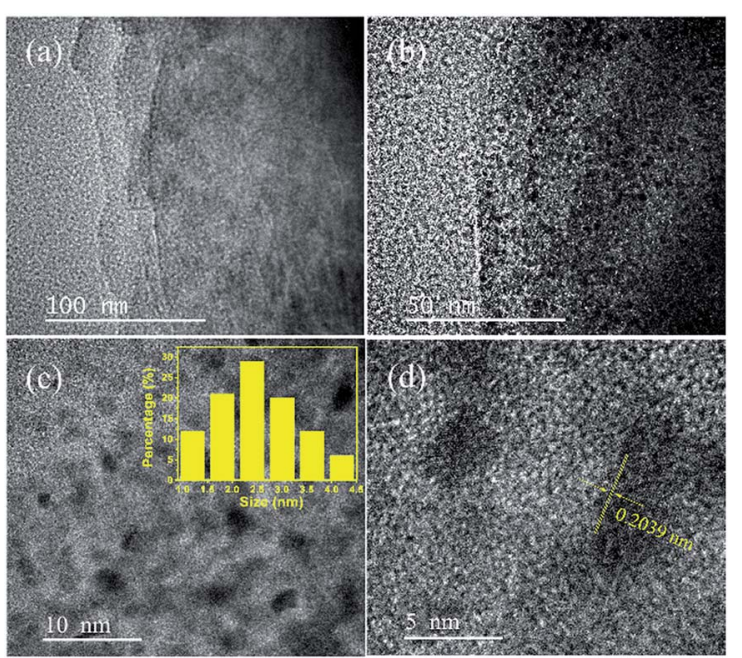

Fig. 2 TEM images (a-c), and HRTEM images (d) of the $\mathrm{Co}_{0.7} \mathrm{Ni}_{0.3} /$ MXene. 
and $\mathrm{F}$ groups on $\mathrm{Ti}_{3} \mathrm{C}_{2} \mathrm{X}_{2}$ surface, which has been confirmed by XPS results. A high resolution TEM (HRTEM) analysis of a representative nanoparticle of $\mathrm{Co}_{0.7} \mathrm{Ni}_{0.3}$ suggests that the assynthesized specimen has a clearly identified lattice fringe space of $0.2039 \mathrm{~nm}$, which is less than that of the (111) plane of pure face-centered cubic (fcc) Co (0.2046 nm), and larger than that of the (111) plane of pure face-centered cubic (fcc) $\mathrm{Ni}$ $(0.2033 \mathrm{~nm})$. These results confirmed the as-synthesized $\mathrm{Co}_{0.7} \mathrm{Ni}_{0.3}$ NPs with an alloy structure. In addition, an energy dispersive X-ray (EDX) spectrum proves the presence of Co and $\mathrm{Ni}$ elements with an atomic ratio of $2.35: 1$ (Fig. $\mathrm{S} 4 \dagger$ ), which is in good agreement with the ICP-AES results (Table $\mathrm{S} 1 \dagger$ ). The elemental mappings of $\mathrm{Ni}$, Co, and $\mathrm{C}$ (Fig. 3) further reveal that Co and Ni elements were homogeneously dispersed throughout the whole MXene. From the above results, it can be seen that the as-synthesized CoNi nanocatalysts have been well dispersed on MXene surface, which benefits to enhancing catalytic property for $\mathrm{AB}$ decomposition in this bimetallic heterogeneous system.

The as-synthesized $\mathrm{Co}_{x} \mathrm{Ni}_{1-x} /$ MXene $(0 \leq x \leq 1)$ NPs have been applied as catalysts for the $\mathrm{AB}$ decomposition at $50{ }^{\circ} \mathrm{C}$ with a constant molar ratio of catalyst $/ \mathrm{AB}=0.02$ (Fig. 4a). A fast hydrogen generation starts immediately without any induction period when the catalyst is mixed with $\mathrm{AB}$ solution under magnetic stirring at $50{ }^{\circ} \mathrm{C}$. Namely, $\mathrm{Co}_{0.7} \mathrm{Ni}_{0.3}$ NPs exhibit the highest catalytic activity for $\mathrm{AB}$ decomposition, and the corresponding TOF value can achieve $87.6 \mathrm{~mol}_{\mathrm{H}_{2}} \mathrm{~mol}_{\text {cat }}{ }^{-1} \mathrm{~min}^{-1}$ at $50{ }^{\circ} \mathrm{C}$. This value is one of the highest values among all the heterogeneous catalytic dehydrogenation of $\mathrm{AB}$ (Table 1). Mass spectrometry (MS) results further confirm the generated $\mathrm{H}_{2}$ and the absence of $\mathrm{NH}_{3}$ in the released gas (Fig. $\mathrm{S} 5 \dagger$ ). Notably, the composition of $\mathrm{Co}$ and $\mathrm{Ni}$ has the obvious effect on the catalytic performance of $\mathrm{Co}_{x} \mathrm{Ni}_{1-x}$ for $\mathrm{AB}$ decomposition. If absence of Co additives, reaction catalyzed by pure Ni shows the lowest catalytic activity and hydrogen generation quantity. By alloying Co to $\mathrm{Ni}$, the catalytic activity and selectivity is significantly
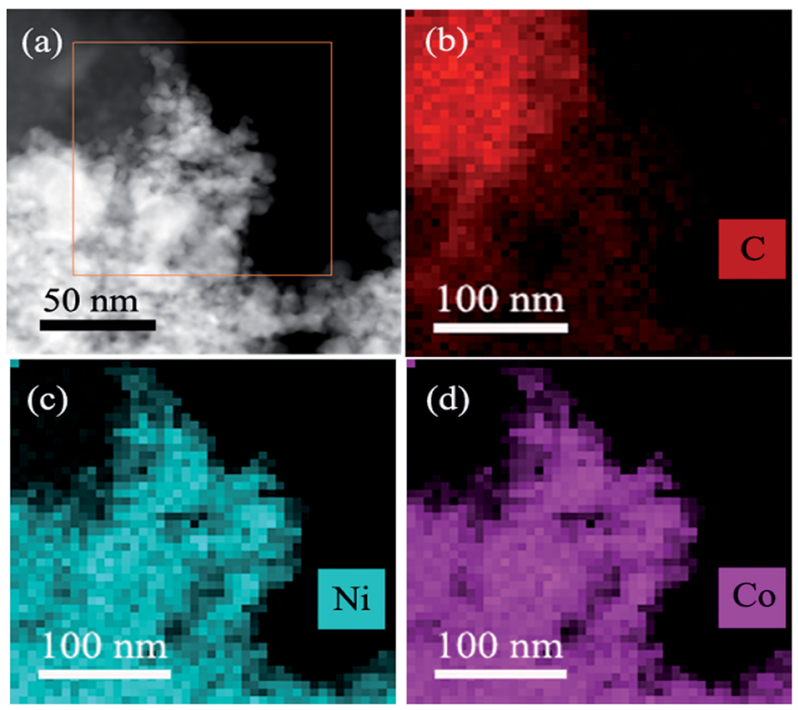

Fig. 3 The STEM-HAADF images of the $\mathrm{CO}_{0.7} \mathrm{Ni}_{0.3} / \mathrm{MXene}(\mathrm{a})$ and the corresponding elemental mapping images for $\mathrm{C}$ (b), $\mathrm{Ni}$ (c) and $\mathrm{Co}(\mathrm{d})$.
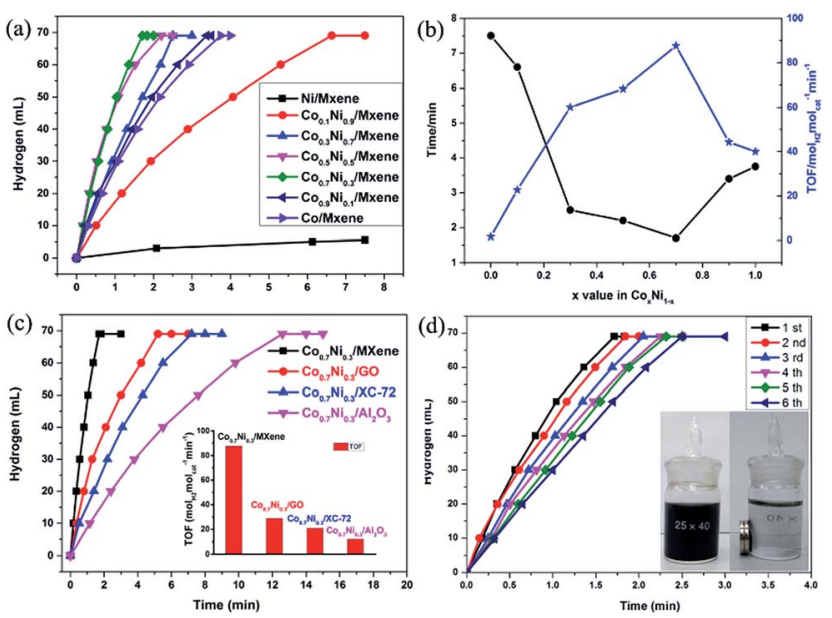

Fig. 4 Time course plots for $\mathrm{H}_{2}$ generation from $\mathrm{AB}$ decomposition with different Co/Ni molar ratios $(0 \leq x \leq 1)$ (a); the corresponding reaction time and TOF (b); over $\mathrm{Co}_{0.7} \mathrm{Ni}_{0.3} / \mathrm{MXene}, \mathrm{Co}_{0.7} \mathrm{Ni}_{0.3} / \mathrm{GO}$, $\mathrm{Co}_{0.7} \mathrm{Ni}_{0.3} / \mathrm{XC}-72$ and $\mathrm{Co}_{0.7} \mathrm{Ni}_{0.3} / \mathrm{Al}_{2} \mathrm{O}_{3}$ at $50{ }^{\circ} \mathrm{C}$ (c); catalyzed by $\mathrm{CO}_{0.7} \mathrm{Ni}_{0.3} / \mathrm{MXene}$ from 1 st to 6 th cycles (d). The molar ratio of metal/ $\mathrm{AB}=0.02$.

Table 1 Catalytic activities of different catalysts for $A B$ decomposition

\begin{tabular}{|c|c|c|c|c|}
\hline Catalyst & $\begin{array}{l}\text { Temp. } \\
(\mathrm{K})\end{array}$ & $\begin{array}{l}\text { TOF } \\
\left(\operatorname{mol}_{\mathrm{H}_{2}} \mathrm{~mol}_{\text {cat }}^{-1}\right. \\
\left.\min ^{-1}\right)\end{array}$ & $\begin{array}{l}E_{\mathrm{a}} \\
\left(\mathrm{kJ} \mathrm{mol}^{-1}\right)\end{array}$ & Ref. \\
\hline \multirow[t]{2}{*}{ CoNi/MXene } & 323 & 87.6 & 36.9 & This work \\
\hline & 303 & 39.1 & 36.9 & This work \\
\hline CuCo@MIL-101 & 298 & 19.6 & - & 15 \\
\hline $\begin{array}{l}\mathrm{Cu}_{0.8} \mathrm{Co}_{0.2} \mathrm{O} @ g r a p h e n e \\
\text { oxide }\end{array}$ & 298 & 70 & 43.5 & 29 \\
\hline Cu@Co/Co & 303 & 8.36 & 51.3 & 30 \\
\hline NiCu@C nanofiber & 298 & 3.6 & 285.9 & 31 \\
\hline $\mathrm{CuCo}_{2} \mathrm{O}_{4} / \mathrm{Ti}$ & 298 & 44 & 23.6 & 32 \\
\hline $\mathrm{Cu}_{0.49} \mathrm{Co}_{0.51} / \mathrm{C}$ & 298 & 45 & 51.9 & 33 \\
\hline $\mathrm{Ni} / \mathrm{CNTS}$ & 298 & 26.2 & 32.3 & 16 \\
\hline Co/PSMA & 298 & 25.7 & 34 & 34 \\
\hline Co/graphene & 298 & 18.5 & 27.41 & 35 \\
\hline $\mathrm{Co} / \mathrm{rGO}$ & 298 & 13.8 & 32.7 & 36 \\
\hline $\begin{array}{l}\mathrm{Cu}_{0.1} @ \mathrm{Co}_{0.45} \mathrm{Ni}_{0.45} / \\
\text { graphene }\end{array}$ & 298 & 15.5 & 58 & 37 \\
\hline Au-Co@CN & 298 & 28.4 & - & 38 \\
\hline Ag@Co/graphene & 298 & 10.23 & 20.03 & 8 \\
\hline Au@AuCo/CNT & 298 & 13.24 & 41.9 & 39 \\
\hline Pd@Co/graphene & 298 & 408 & - & 40 \\
\hline Cu@FeNi & 303 & 114 & 44 & 41 \\
\hline Cu@FeCo & 303 & 10.5 & 38.75 & 42 \\
\hline
\end{tabular}

improved. When the molar ratio of Co ( $x$ value) increases from 0.1 to 0.7 , the reaction time decreases from $6.6 \mathrm{~min}$ to $1.7 \mathrm{~min}$ and the corresponding TOF value increases from $22.7 \mathrm{~mol}_{\mathrm{H}_{2}} \mathrm{~mol}_{\mathrm{cat}}{ }^{-1} \mathrm{~min}^{-1}$ to $87.6 \mathrm{~mol}_{\mathrm{H}_{2}} \mathrm{~mol}_{\mathrm{cat}}{ }^{-1} \mathrm{~min}^{-1}$, respectively. However, when the molar ratio of Co reaches 1.0, namely, no addition of $\mathrm{Ni}$, the reaction is completed in $3.75 \mathrm{~min}$. Obviously, the catalytic activity of the $\mathrm{Co}_{x} \mathrm{Ni}_{1-x}$ alloy is better than those of pure $\mathrm{Ni}$ and $\mathrm{Co}$. The reason for the enhanced performance of $\mathrm{Co}_{x} \mathrm{Ni}_{1-x}$ alloy may be mainly 
resulted from the synergetic effect between $\mathrm{Co}$ and $\mathrm{Ni}$, which can efficiently tune surface electronic states of bimetallic nanoparticles, particularly related to local strain and effective atomic coordination number at the surface, leading an apparent improvement for $\mathrm{AB}$ decomposition.

Furthermore, the carrier materials also play an important role on determining the catalytic performance for $\mathrm{AB}$ decomposition. In order to evaluate the effect of the carrier materials on the catalytic performances toward the $\mathrm{AB}$ decomposition, $\mathrm{Co}_{0.7} \mathrm{Ni}_{0.3} \mathrm{NPs}$ are loaded on different carriers such as GO $\left(\mathrm{Co}_{0.7} \mathrm{Ni}_{0.3} / \mathrm{GO}\right)$, XC-72 $\left(\mathrm{Co}_{0.7} \mathrm{Ni}_{0.3} / \mathrm{XC}-72\right)$, and $\mathrm{Al}_{2} \mathrm{O}_{3}\left(\mathrm{Co}_{0.7} \mathrm{Ni}_{0.3} /\right.$ $\mathrm{Al}_{2} \mathrm{O}_{3}$ ) and their catalytic activities toward $\mathrm{AB}$ decomposition at $50{ }^{\circ} \mathrm{C}$ with a constant molar ratio of catalyst $/ \mathrm{AB}=0.02$ are shown in Fig. 4c. The $\mathrm{AB}$ decomposition catalyzed by $\mathrm{Co}_{0.7} \mathrm{Ni}_{0.3} /$ $\mathrm{GO}, \mathrm{Co}_{0.7} \mathrm{Ni}_{0.3} / \mathrm{XC}-72$ and $\mathrm{Co}_{0.7} \mathrm{Ni}_{0.3} / \mathrm{Al}_{2} \mathrm{O}_{3}$ are completed in 5.2, 7.2 and $12.6 \mathrm{~min}$, respectively, and the corresponding TOF values are 28.8, 20.6 and $11.9 \mathrm{~mol}_{\mathrm{H}_{2}} \mathrm{~mol}_{\mathrm{cat}}{ }^{-1} \mathrm{~min}^{-1}$ in the same reaction condition. Compared to $\mathrm{Co}_{0.7} \mathrm{Ni}_{0.3} / \mathrm{GO}, \mathrm{Co}_{0.7} \mathrm{Ni}_{0.3} / \mathrm{XC}$ 72 and $\mathrm{Co}_{0.7} \mathrm{Ni}_{0.3} / \mathrm{Al}_{2} \mathrm{O}_{3}$, the prepared $\mathrm{Co}_{0.7} \mathrm{Ni}_{0.3} / \mathrm{MXene}$ show higher catalytic kinetics. The superior catalytic performance is mainly attributed that strong interface interaction between metal and carrier, especially for the defect-rich or oxygen groupdeficient surfaces on MXene. Such interface interaction is considered to favour the formation of a tunable electronic state of metal NPs, which enhances the $\mathrm{AB}$ decomposition.

In order to obtain the activation energy $\left(E_{\mathrm{a}}\right)$ of the $\mathrm{AB}$ decomposition catalyzed by $\mathrm{Co}_{0.7} \mathrm{Ni}_{0.3} / \mathrm{MXene}$ catalysts, the reactions at different temperatures $\left(30-60{ }^{\circ} \mathrm{C}\right)$ were carried out. Fig. S6a $\uparrow$ shows that the plots of the generated $\mathrm{H}_{2}$ versus reaction time for $\mathrm{AB}$ decomposition in the presence of $\mathrm{Co}_{0.7} \mathrm{Ni}_{0.3}$ catalyst at different temperatures. The Arrhenius plot of ln TOF vs. $1 / T$ for the catalyst is plotted in Fig. S6b, $\dagger$ and $E_{\mathrm{a}}$ is calculated to be $36.9 \mathrm{~kJ} \mathrm{~mol}^{-1}$.

For the practical application of catalysts, the durability/ stability of catalysts is the key point. Therefore, the durability of the $\mathrm{Co}_{0.7} \mathrm{Ni}_{0.3} / \mathrm{MXene}$ nanocatalyst up to fifth run for $\mathrm{AB}$ decomposition was characterized by adding additional aliquots ( $1 \mathrm{mmol}$ ) of $\mathrm{AB}$ to the catalyst after the reaction completion for the last run. It is evident from Fig. $4 \mathrm{~d}$, it is found that a little decrease after a six-time recycle test was seen and the reaction time is prolonged from 1.7 to $2.5 \mathrm{~min}$, indicating the asprepared $\mathrm{Co}_{0.7} \mathrm{Ni}_{0.3} /$ MXene possess a moderated durability in $\mathrm{AB}$ decomposition. It is due to that the functional $\mathrm{OH}$ and $\mathrm{F}$ groups on $\mathrm{Ti}_{3} \mathrm{C}_{2} \mathrm{X}_{2}$ surface, as an anchor, can stabilize the CoNi NPs, avoid the aggregation of CoNi NPs during the reaction process, which is confirmed by TEM images. As clearly seen from the TEM images (Fig. S7 $\dagger$ ), the CoNi NPs can well disperse on MXene surface and there is no obvious aggregation of the CoNi NPs on MXene. Furthermore, the in situ synthesized NPs are magnetic and thus can be separated from the reaction solution by an external magnet (Fig. 4d, inside), which makes the practical recycling application of the NPs more convenient.

\section{Conclusions}

In summary, cost-effective bimetallic CoNi NPs are well dispersed on MXene surfaces by a simple one-step wet-chemical method. Wherein the MXene plays an important role in stabilizing the CoNi NPs, leading a fine dispersion and good stability of the synthesized nanocatalyst in this heterogeneous system. By optimizing the fraction of Co component in Co-Ni system, the synthesized $\mathrm{Co}_{0.7} \mathrm{Ni}_{0.3} / \mathrm{MXene}$ have been proven to the most reactive nanocatalyst in this family reward to $\mathrm{AB}$ decomposition with $100 \%$ of $\mathrm{H}_{2}$ selectivity and excellent catalytic performance of $87.6 \mathrm{~mol}_{\mathrm{H}_{2}} \mathrm{~mol}_{\mathrm{cat}}{ }^{-1} \mathrm{~min}^{-1}$ at $50{ }^{\circ} \mathrm{C}$. Additionally, the synergetic effect between CoNi NPs and MXene also improve the kinetic toward $\mathrm{AB}$ decomposition. This simple synthetic method can be easily extended to facile preparation other MXene supported metal NPs.

\section{Conflicts of interest}

There are no conflicts to declare.

\section{Acknowledgements}

This work was financially supported by the National Natural Science Foundation of China (Project No. 51306166 and 51206101).

\section{Notes and references}

1 S. Young, Nature, 2001, 414, 487-488.

2 P. P. Edwards, V. L. Kuznetsov and N. P. Brandon, Energy Policy, 2008, 36, 4356-4362.

3 X. Yang and Q. Xu, Chin. J. Catal., 2016, 37, 1594-1599.

4 H. L. Wang, Q. L. Zhu, R. Zou and Q. Xu, Chem, 2017, 2, 5280.

5 J. Kotowicz, L. Bartela, D. Wecel and K. Dubiel, Energy, 2017, 118, 156-171.

6 H. M. Chen, C. K. Chen, R. S. Liu, L. Zhang, J. Zhang and D. P. Wilkinson, Chem. Soc. Rev., 2012, 41, 5654-5671.

7 J. Graetz, Chem. Soc. Rev., 2009, 38, 73-82.

8 L. Yang, W. Luo and G. Cheng, ACS Appl. Mater. Interfaces, 2013, 5, 8231-8240.

9 J. Cheng, X. Gu, P. Liu, H. Zhang, L. Ma and H. Su, Appl. Catal., B, 2017, 218, 460-469.

10 J. M. Yan, Z. L. Wang, H. L. Wang and Q. Jiang, J. Mater. Chem., 2012, 22, 10990-10993.

11 O. Metin, S. Duman, M. Dinc and S. Ozkar, J. Phys. Chem. C, 2011, 115, 10736-10743.

12 M. Chandra and Q. Xu, J. Power Sources, 2006, 156, 190-194.

13 W. W. Zhan, Q. L. Zhu and Q. Xu, ACS Catal., 2016, 6, 68926905.

14 C. Yu, J. Fu, M. Muzzio, T. Shen, D. Su, J. Zhu and S. Sun, Chem. Mater., 2017, 29, 1413-1418.

15 J. Li, Q. L. Zhu and Q. Xu, Catal. Sci. Technol., 2015, 5, 525530.

16 W. Feng, L. Yang, N. Cao, C. Du, H. M. Dai, W. Luo and G. Z. Cheng, Int. J. Hydrogen Energy, 2014, 39, 3371-3380.

17 Q. L. Zhu, J. Li and Q. Xu, J. Am. Chem. Soc., 2013, 135, 10210-10213.

18 F. Z. Song, Q. L. Zhu, X. C. Yang and Q. Xu, ChemNanoMat, 2016, 2, 1003. 
19 W. Y. Chen, J. Ji, X. Z. Duan, G. Qian, P. Li, X. G. Zhou, D. Chen and W. K. Yuan, Chem. Commun., 2014, 50, 21422144.

20 S. Akbayrak and S. Ozkar, ACS Appl. Mater. Interfaces, 2012, 4, 6302-6310.

21 X. Xie, S. Chen, W. Ding, Y. Nie and Z. Wei, Chem. Commun., 2013, 49, 10112-10114.

22 M. Naguib, J. Come, B. Dyatkin, V. Presser, P.-L. Taberna and P. Simon, Electrochem. Commun., 2012, 16, 61-64.

23 X. Xie, Y. Xue, L. Li, S. Chen, Y. Nie, W. Ding and Z. D. Wei, Nanoscale, 2014, 6, 11035-11040.

24 M. Ghidiu, M. R. Lukatskaya, M. Q. Zhao, Y. Gogotsi and M. W. Barsoum, Nature, 2014, 516, 78-81.

25 M. Naguib, M. Kurtoglu, V. Presser, J. Lu, J. Niu, M. Heon, L. Hultman, Y. Gogotsi and M. W. Barsoum, Adv. Mater., 2011, 23, 4248-4253.

26 Q. Peng, J. Guo, Q. Zhang, J. Xiang, B. Liu, A. Zhou, R. Liu and Y. Tian, J. Am. Chem. Soc., 2014, 136, 4113-4116.

27 X. Li, G. Fan and C. Zeng, Int. J. Hydrogen Energy, 2014, 39, 14927-14934.

28 X. Li, C. Zeng and G. Fan, Int. J. Hydrogen Energy, 2015, 40, 3883-3891.

29 K. Feng, J. Zhong, B. Zhao, H. Zhang, L. Xu, X. Sun and S.-T. Lee, Angew. Chem., Int. Ed., 2016, 55, 11950-11954.

30 Y. S. Du, N. Cao, L. Yang, W. Luo and G. Z. Cheng, New J. Chem., 2013, 37, 3035-3042.
31 A. Yousef, N. A. M. Barakat, M. El-Newehy and H. Y. Kim, Int. J. Hydrogen Energy, 2012, 37, 17715-17723.

32 Q. B. Liu, S. J. Zhang, J. Y. Liao, K. J. Feng, Y. Y. Zheng, B. G. Pollet and H. Li, J. Power Sources, 2017, 355, 191-198.

33 A. Bulut, M. Yurderi, I. E. Ertas, M. Celebi, M. Kaya and M. Zahmakiran, Appl. Catal., B, 2016, 180, 121-129.

34 Ö. Metin and S. Özkar, Int. J. Hydrogen Energy, 2011, 36, 1424-1432.

35 M. Li, J. Hu and H. Lu, Catal. Sci. Technol., 2016, 6, 71867192.

36 L. Yang, N. Cao, C. Du, H. Dai, K. Hu, W. Luo and G. Cheng, Mater. Lett., 2014, 115, 113-116.

37 X. Meng, L. Yang, N. Cao, C. Du, K. Hu, J. Su, W. Luo and G. Cheng, ChemPlusChem, 2014, 79, 325-332.

38 L. T. Guo, Y. Y. Cai, J. M. Ge, Y. N. Zhang, L. H. Gong and X. H. Li, ACS Catal., 2014, 5, 388-392.

39 L. Yang, W. Luo and G. Cheng, ACS Appl. Mater. Interfaces, 2013, 5, 8231-8240.

40 J. Wang, Y. L. Qin, X. Liu and X. B. Zhang, J. Mater. Chem., 2012, 22, 12468-12470.

41 H. L. Wang, J. M. Yang, Z. L. Wang and Q. Jiang, Int. J. Hydrogen Energy, 2012, 37, 10229-10235.

42 F. Qiu, Y. Dai, L. Li, C. Xu, Y. Huang and C. Chen, Int. J. Hydrogen Energy, 2014, 39, 436-441. 